\title{
A biomechanical matched-pair comparison of two different locking plates for tibial diaphyseal comminuted fracture: carbon fiber-reinforced poly-ether-ether-ketone (CF-PEEK) versus titanium plates
}

\author{
Kaihua Zhou ${ }^{1,2}$, Xiaojian $\mathrm{He}^{2}$, Xingguang Tao ${ }^{2}$, Fugen $\mathrm{Pan}^{2}$ and Huilin Yang ${ }^{1 *}$
}

\begin{abstract}
Background: Several methods have been proposed to reduce plate construct stiffness and promote secondary bone healing. In this study, we explored the stiffness and strength of the new carbon fiber-reinforced poly-etherether-ketone (CF 50) plate compared with the titanium alloy plate (Ti6Al4V).

Methods: Titanium and CF-PEEK locking plates were tested in a tibial non-osteoporotic diaphyseal comminuted fracture model to determine construct stiffness in axial compression, torsion, and bending. Subsequently, constructs were loaded until construct failure to determine construct strength.

Results: Relative to the titanium locking plate, the stiffness of the CF-PEEK locking plate was $6.8 \%$ and $30.8 \%$ lower in $200 \mathrm{~N}$ and $700 \mathrm{~N}$ axial compression, respectively $(P<0.05), 64.9 \%$ lower in torsion $(P<0.05)$, and $48.9 \%$ lower in bending $(P<0.05)$. The strength of the CF-PEEK locking plate was only $2.6 \%$ lower under axial compression, $7.8 \%$ lower in torsion, and $4.8 \%$ lower in bending than the titanium locking plate $(P>0.05)$.

Conclusions: The CF-PEEK locking plate significantly reduced axial, torsion, and bending stiffness compared with the titanium locking plate. Nonetheless, axial, torsional, and bending strength showed only a modest reduction. Considering its other advantages, which include radiolucency and artifact-free imaging, the CF-PEEK locking plate therefore deserves further clinical investigation.
\end{abstract}

Keyword: Tibial fracture, Internal fixation, Biomechanics, Carbon fiber-reinforced poly-ether-ether-ketone (CF-PEEK)

Tibial diaphyseal fracture is a common clinical condition, especially in high-energy traffic accident injuries [1]. For those who need surgical intervention, the intramedullary nail is the gold standard for treatment; however, for those patients with a narrow cavity or immature epiphysis, we

\footnotetext{
* Correspondence: suzhouspine1@163.com

Kaihua Zhou and Xiaojian He are co-first authors.

'Department of Orthopedics, the First Affiliated Hospital of Soochow University, No. 899, Pinghai Road, Soochow 215006, China

Full list of author information is available at the end of the article
}

often use plates for effective fixation, thereby providing a good mechanical environment for fracture healing [2]. For simple fractures, we traditionally use compression plates to promote primary bone healing by absolute stability [3]. For comminuted fractures, we recommended bridge techniques with locking plates to increase callus formation $[4$, 5]. The locking plates allow for the use of the biological osteosynthesis (BO) fixation principle that emphasizes preservation of blood supply. However, clinical complications such as nonunion, delay union, and plate breakage

(c) The Author(s). 2020 Open Access This article is licensed under a Creative Commons Attribution 4.0 International License, which permits use, sharing, adaptation, distribution and reproduction in any medium or format, as long as you give appropriate credit to the original author(s) and the source, provide a link to the Creative Commons licence, and indicate if changes were made. The images or other third party material in this article are included in the article's Creative Commons licence, unless indicated otherwise in a credit line to the material. If material is not included in the article's Creative Commons licence and your intended use is not permitted by statutory regulation or exceeds the permitted use, you will need to obtain permission directly from the copyright holder. To view a copy of this licence, visit http://creativecommons.org/licenses/by/4.0/. The Creative Commons Public Domain Dedication waiver (http://creativecommons.org/publicdomain/zero/1.0/) applies to the data made available in this article, unless otherwise stated in a credit line to the data. 
are not uncommon, accounting for about $3.5-13.3 \%$ of all cases [6-12].

There are six main reasons for nonunion, delay union, and plate breakage: (1) improper selection of plate, (2) poor reduction of fracture, (3) unstable fixation, (4) improper selection of screw number and configuration, (5) excess early weight-bearing, and (6) infection. For implants, we have done a great deal of research on the length of the plate and the number and configuration of the screws [13, 14]. We also replaced stainless steel $(316$ L) with titanium alloy (Ti6Al4V), which has lower stiffness and induces less soft tissue reaction. Because the frequently used metal locking plates may have relatively high stiffness, they can suppress interfragmentary motion to a level insufficient for the optimal promotion of secondary bone healing [15]. Secondary bone healing is induced by interfragmentary micromotion in the millimeter range [16], with the optimal range of micromotion being $0.2-1.0 \mathrm{~mm}$ [17, 18]. Deficient callus formation can lead to either delayed union or nonunion with late hardware failure of the locking plate $[19,20]$. Reducing the elastic modulus of the plate can also reduce the stress shielding effect. Therefore, the selection of a plate material with an appropriate elastic modulus is a problem worthy of study. With new developments in materials science, we found that plates made with carbon fiber-reinforced poly-ether-ether-ketone had a similar elastic modulus to that of the bone cortex. In the literature, there have been successful cases using CF-PEEK implants in spine, tumors, and arthroplasty [21-25]. In trauma, CF-PEEK plates have been used for proximal humeral and distal radial fractures, with clinical outcomes better than with titanium plates [26-29]. However, there has been little research done on the use of CF-PEEK plates in lower limb fractures.

The aim of this study was to test the hypothesis that the CF-PEEK locking plate can significantly reduce stiffness compared with the titanium locking plate while retaining its strength. A less-stiff yet still strong construct of the CF-PEEK locking plate could potentially enhance bone healing by promoting early interfragmentary motion.

\section{Materials and methods}

Titanium alloy (Ti6Al4V) and CF-PEEK (CF50) locking plates were tested in a tibial non-osteoporotic diaphyseal comminuted fracture plating configuration under axial compression, torsion, and bending as in previous studies $[13,30]$. The stiffness and strength of the titanium and CF-PEEK plates were determined by progressive loading of the non-osteoporotic tibial diaphysis until construct failure.
Implants and specimens

The generic titanium and CF-PEEK locking plates were designed to resemble standard broad $4.5-\mathrm{mm}$ locking plates and screws. The plates were $13.5-\mathrm{mm}$ wide and 181-mm long and had 10 holes with a space of 18 $\mathrm{mm}$ between holes. Locking screws had a $4.5-\mathrm{mm}$ diameter bone thread with 1-mm pitch and a four-fluted selftapping feature. The titanium plates were custom manufactured from surgical grade titanium alloy (Ti6Al4V) by a company specializing in the production of orthopedic implants (Watson, Jiangsu, Changzhou). CF-PEEK plates were manufactured at the same size as the titanium plates, with the PEEK material containing 50\% carbon fiber. The locking screws used with the CF-PEEK plate were made of the same material as the titanium locking screws and used in the same way as in ordinary clinical use [26-29]. The titanium locking plates and CF-PEEK plates were evaluated in a standard plating configuration in tibial diaphysis surrogates with a $10-\mathrm{mm}$ fracture gap as comminuted fracture [30]. For these surrogates, we used the medium-size fourth-generation composite Sawbones tibia (\#3401; Pacific Research Laboratories, Vashon, WA, USA). The plate was applied with three locking screws placed in the first, second, and fourth holes in each side (Fig. 1). All screws were tightened to 4 $\mathrm{Nm}$ with the plate at $1 \mathrm{~mm}$ of elevation from the surrogate surface to simulate biological fixation with preservation of periosteal perfusion. Two holes were left empty over the fracture gap, yielding a plate span of $48 \mathrm{~mm}$ that bridged the gap.

\section{Loading}

The titanium and CF-PEEK locking plate groups were tested in axial compression, torsion, and bending with a biaxial material testing system (Instron 3365, Norwood, MA, USA) in the non-osteoporotic bone surrogate specimens (Fig. 2). A motion tracking system (Optitrack Flex13, Natural Point Inc., Corvallis, OR, USA) was used to record the data. Both groups were tested until construct failure in the axial compression, torsion, and bending loading mode, which required the use of a total of thirty-six specimens.

\section{Axial tests}

For the axial compression test, the specimen was held vertical, while axial compression was applied by a disc at the proximal end of the specimen with the distal end embedded. The preload was $50 \mathrm{~N}$, and the loading speed was $5 \mathrm{~mm} / \mathrm{min}$ to $200 \mathrm{~N}$ and $700 \mathrm{~N}$ compression. Compressive stiffness was recorded, and interfragmentary motion under $200 \mathrm{~N}$ axial compression was also recorded at the near and far cortex (Fig. 3). 

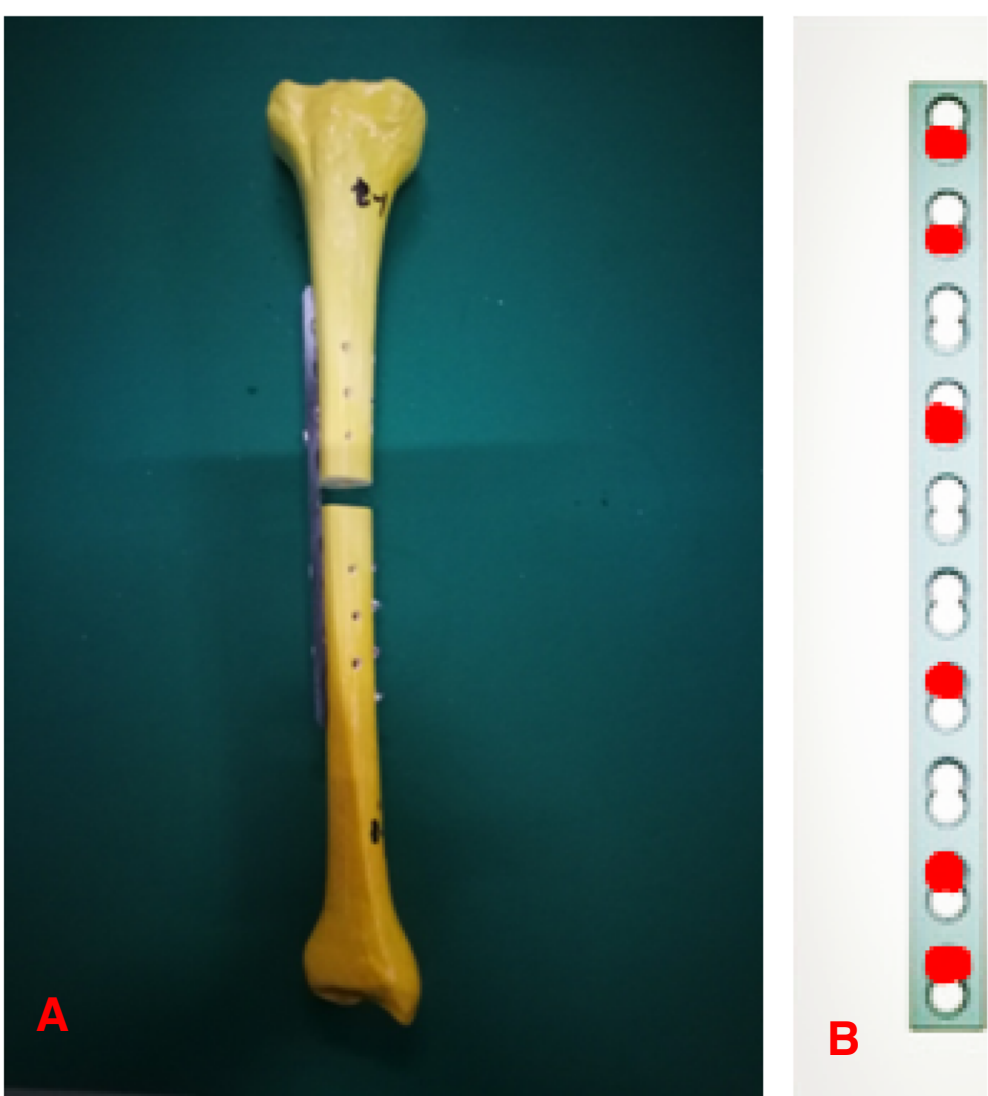

Fig. 1 Test construct design. a The titanium locking plates and CF-PEEK plates were evaluated in a standard plating configuration in tibial diaphysis surrogates with a 10-mm fracture gap as comminuted fracture. b The plate was applied with three locking screws, which were placed in the first, second, and fourth holes in each side (red spots)

\section{Torsion tests}

Torsion was applied around the diaphyseal axis. The two ends of the specimen were fixed in the MTS planar biaxial test system, and the machine was driven to apply torque to the specimen at a speed of $0.1 / \mathrm{s}$, with the proximal end of the fracture being twisted to the outside. The rigidity and strength were recorded when the construct failed.

\section{Bending tests}

Four-point bending was applied to generate a constant bending moment over the entire plate length. The upper and lower cylindrical supports were separated by 70 and $180 \mathrm{~mm}$, respectively. The plate was fixed on the tension side to induce bending in a gap-closing mode at a speed of $5 \mathrm{~mm} / \mathrm{min}$. The rigidity and strength were recorded when the construct failed.
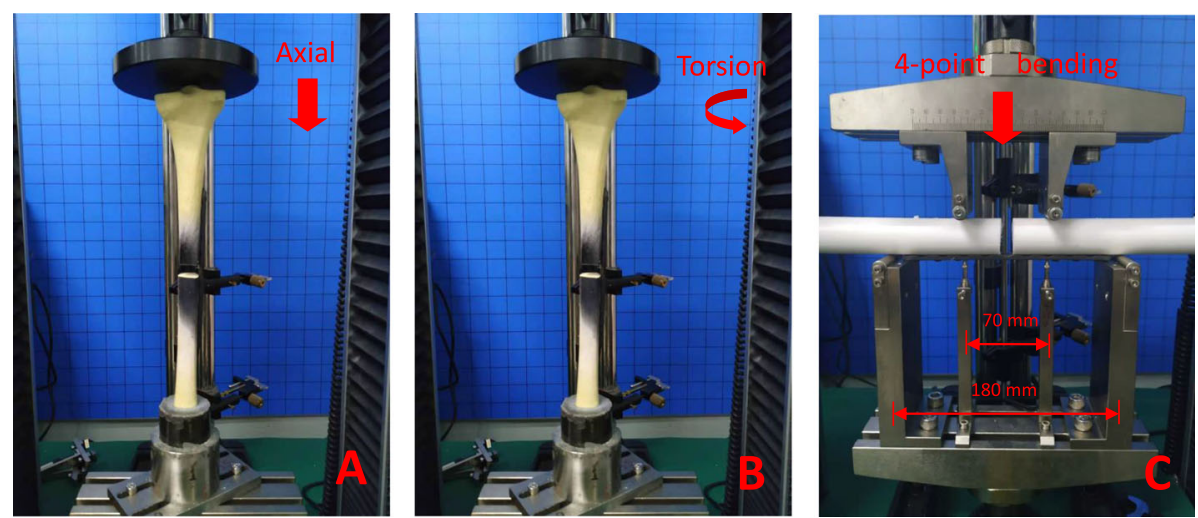

Fig. 2 Construct stiffness and strength were evaluated under three loading conditions. a axial compression test, the red dot represents the location of motion-tracking sensors; $\mathbf{b}$ torsion test; $\mathbf{c}$ four point bending test in a gap-closing direction 


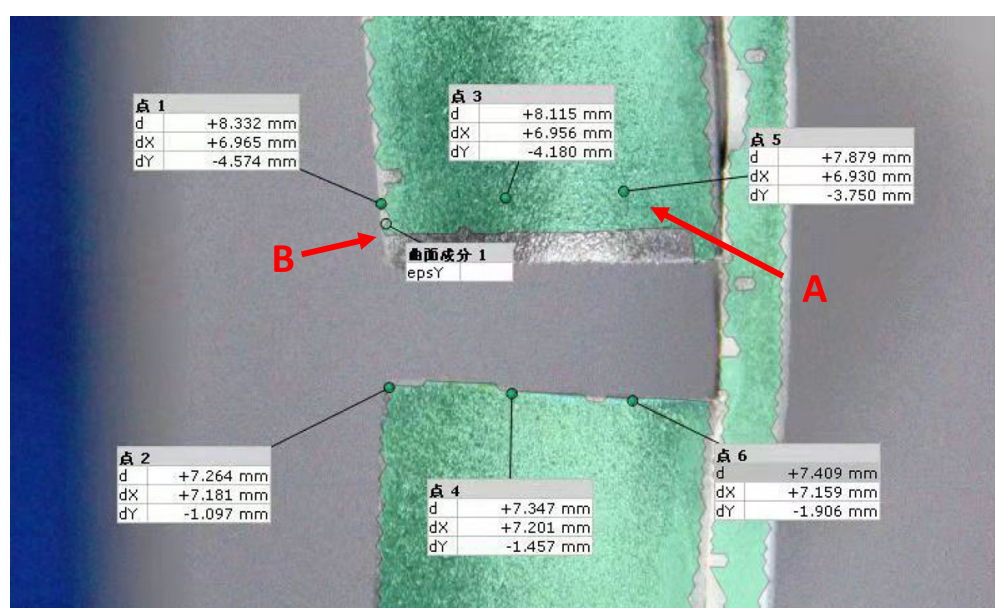

Fig. 3 Interfragmentary motion under $200 \mathrm{~N}$ axial compression was also recorded at the near cortex (a) and far cortex (b)

\section{Outcome evaluation}

Construct stiffness was calculated from loaddisplacement data. Axial stiffness was calculated by dividing the axial load amplitude by the actuator displacement amplitude. Torsional stiffness was calculated by dividing the torsion amplitude by the amplitude of actuator rotation around the diaphyseal axis. Bending stiffness was calculated in terms of flexural rigidity [31]. Construct strength was defined as the peak load during progressive loading to construct failure. Construct failure was defined by either the first visible occurrence of failure of internal fixation, whether by fracture of the diaphysis through the screw hole at the plate end; plate or screw bending or breakage; fracture through the screw hole at the plate end; or a subsidence threshold at the fracture site whichever occurred first. A subsidence threshold of $10 \mathrm{~mm}$ in axial compression, $15^{\circ}$ in torsion, and $10 \mathrm{~mm}$ in bending was deemed indicative of the onset of clinical construct failure as previous studies [31-33].

\section{Statistical analysis}

SPSS 23.0 statistical software was used to analyze the data. One-way ANOVA was used for comparisons between multiple groups; Student's $t$ tests were used for comparisons between two groups. Differences are considered to be statistically significant when $P$ values < 0.05 .

\section{Results}

Construct stiffness (Table 1)

With $200 \mathrm{~N}$ axial compression, the stiffness of the CF-PEEK plate was $6.8 \%$ lower than that of the titanium plate $(169.83 \pm 3.74 \mathrm{~N} / \mathrm{mm}$ compared with $182.15 \pm 5.53 \mathrm{~N} / \mathrm{mm}, P<0.05)$. The near cortex displacement of the CF-PEEK locking plate was $31.4 \%$ larger than that of the titanium plating plate $(0.51 \pm$ $0.05 \mathrm{~mm}$ compared with $0.35 \pm 0.02 \mathrm{~mm}, P<0.05)$. The far cortex displacement of the CF-PEEK locking plate was $22.6 \%$ larger than that of the titanium locking plate $(0.93 \pm 0.02 \mathrm{~mm}$ compared with $0.72 \mathrm{~mm} \pm$ 0.01, $P<0.05$ ) (Fig. 4).

In $700 \mathrm{~N}$ axial compression, the stiffness of the CFPEEK plate was $30.8 \%$ lower than that of the titanium plate $(155.05 \pm 3.79$ compared with $224.19 \pm 16.62 \mathrm{~N} /$ mm, $P<0.05)$.

In the torsion test, the rigidity of the CF-PEEK plate was $59.4 \%$ lower than that of the titanium plate $(0.13 \pm$ 0.01 compared with $\left.0.32 \pm 0.09 \mathrm{Nm}^{2} / \mathrm{deg}, P<0.05\right)$.

In the bending test, the rigidity of the CF-PEEK locking plate was $48.8 \%$ lower than that of the titanium locking plate $(0.86 \pm 0.01$ compared with $1.68 \pm 0.01$ $\mathrm{Nm}^{2}, P<0.05$ ) (Fig. 5).

\section{Construct strength in the non-osteoporotic diaphysis (Table 1)}

In axial compression, the CF-PEEK locking construct was only $2.6 \%$ weaker than the titanium locking construct $(1.79 \pm 0.01$ compared with $1.84 \pm 0.02 \mathrm{kN}$, $P>0.05)$. All the constructs failed as a result of failure of internal fixation (Fig. 6). In the torsion and bending test, all the constructs failed by reaching the subsidence threshold at the fracture site. In torsion, the strength in the CF-PEEK locking construct was $7.8 \%$ weaker than that in the titanium locking construct $(4.48 \pm 0.05$ compared with $4.86 \pm 0.23 \mathrm{Nm}, P$ $>0.05)$. In bending, the CF-PEEK locking construct was $4.8 \%$ weaker than the titanium locking construct $(4.21 \pm 0.01$ compared with $4.42 \pm 0.13 \mathrm{Nm}, P>$ 0.05) (Fig. 7). 
Table 1 Stiffness and strength of CF-PEEK locking plate and titanium alloy locking plate

\begin{tabular}{llll}
\hline & CF-PEEK locking plate & Titanium alloy locking plate & $P$ value \\
\hline Stiffness & & & \\
Axia stiffness $(\mathrm{N} / \mathrm{mm})$ & & & \\
$\quad 200 \mathrm{~N}$ & $169.83 \pm 3.74$ & $182.15 \pm 5.53$ & $P<0.05$ \\
$700 \mathrm{~N}$ & $155.05 \pm 3.79$ & $224.19 \pm 16.62$ & $P<0.05$ \\
Torsional rigidity $\left(\mathrm{Nm}^{2} / \mathrm{deg}\right)$ & $0.13 \pm 0.01$ & $0.32 \pm 0.09$ & $P<0.05$ \\
Bending rigidity $\left(\mathrm{Nm}^{2}\right)$ & $0.86 \pm 0.01$ & $1.68 \pm 0.01$ & $P<0.05$ \\
Strength & & & $P<0.05$ \\
$\quad$ Axial $(\mathrm{kN})$ & $1.79 \pm 0.01$ & $1.84 \pm 0.02$ & $P<0.05$ \\
$\quad$ Torsion $(\mathrm{Nm})$ & $4.48 \pm 0.05$ & $4.86 \pm 0.23$ & $P<0.05$ \\
$\quad$ Bending $(\mathrm{Nm})$ & $4.21 \pm 0.01$ & $4.42 \pm 0.13$ & \\
\hline
\end{tabular}

\section{Discussion}

The results of the present study support the hypothesis that a CF-PEEK locking plate can have considerably lower stiffness than a titanium locking plate while retaining its strength. The near and far cortex displacement for both CF-PEEK and titanium locking plates was in the range of $0.2-1.0 \mathrm{~mm}$ micromotion, which is optimal to promote callus formation.

Fracture healing is an extremely complex biological process affected by many factors. It requires a good local mechanical environment. Fracture healing can be divided into primary and secondary healing, with secondary healing depending on callus formation. The formation of callus is affected by the range of micromotion at the fracture end. The stiffness reduction of the plate may benefit micromotion with bridge plating

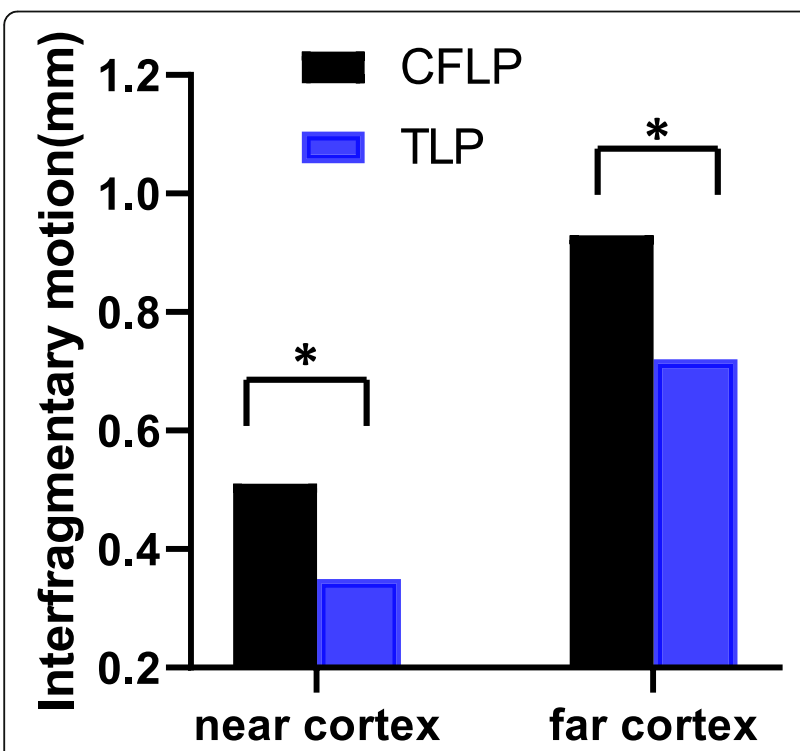

Fig. 4 At $200 \mathrm{~N}$ of axial loading, the fracture site motion in the CFPEEK locking plate (CFLP) was greater than that in the titanium locking plate $(T L P)$. *Significant $(P<0.05)$ osteosynthesis [17, 34]. Biomechanical studies have shown that the elastic modulus of the traditional metal material is much larger than that of the bone cortex (cortex bone $18 \mathrm{GPa}$, stainless steel $200 \mathrm{GPa}$, titanium alloy 106 to $155 \mathrm{GPa}$ ) [32, 35], which may be a cause of nonunions [15, 34, 36]. A systematic review demonstrated a 3.5 -fold increase in the rate of nonunions associated with metal locking plates as compared with intramedullary nailing [37]. Thus, we need plates that are less rigid to improve fracture healing.

There are many methods we can use to reduce the stiffness of locking plate constructs, such as increasing the plate span, plate elevation, or adjusting the screw number and configuration [38-40]. However, the strength of the locking plate is often sacrificed when its stiffness is reduced. Stoffel et al. reported that increasing the titanium plate working span could reduce the compression and torsion stiffness two-fold but also led to a $33 \%$ reduction in strength under axial compression [40]. Alternatively, increasing the plate elevation from 2 to 6 $\mathrm{mm}$ was reported to yield a $10 \%$ to $15 \%$ decrease in both axial and torsional rigidity [38]. However, $5 \mathrm{~mm}$ of plate elevation decreased construct strength in axial compression by $63 \%$ [40].

We also can choose other materials to produce the plate, such as calcium phosphate, magnesium alloys, or absorbable and degradable materials such as polylactic acid and polyhydroxyacetic acid to replace the traditional metal materials [41]. Although animal experiments showed that the stiffness and stress shielding can thereby be significantly reduced, the strength of the plate became poor. In addition, the degradation rate of the absorbable plate is difficult to control, especially in the internal fixation of long bone fractures $[42,43]$. Over the past years, poly-ether-ether-ketone (PEEK) has seen increasing use in medical materials. Through technical innovation, we embedded carbon fibers (CF) into PEEK in different directions to form 

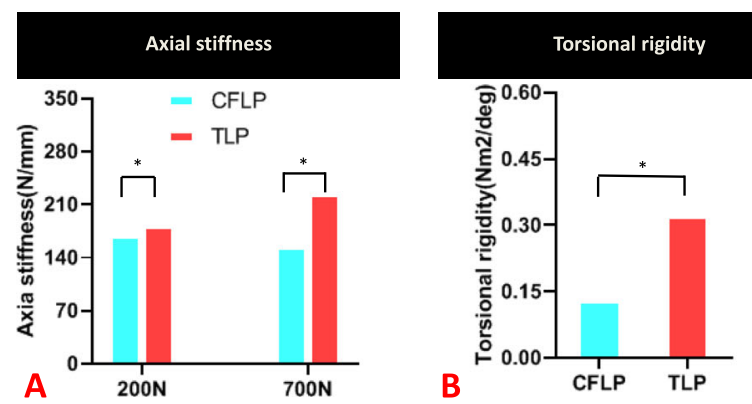

Bending rigidity

B

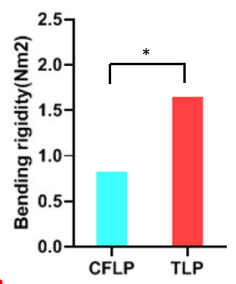

Fig. 5 Relative to the titanium locking plate (TLP), the stiffness of the CF-PEEK locking plate (CFLP) was 6.8\% and $30.8 \%$ lower in $200 \mathrm{~N}$ and $700 \mathrm{~N}$ axial compression, respectively, 59.5\% lower in torsion, and $48.9 \%$ lower in bending. *Significant $(P<0.05)$

a new composite material, CF-PEEK. The elastic modulus of CF-PEEK is smaller than that of metal plates and closer to that of cortical bone. The stiffness and strength are significantly improved and can fix the fracture firmly without losing the original advantages of PEEK.

In the axial compression, torsion, and bending tests, the stiffness in the CF-PEEK locking plate decreased compared with the titanium locking plate. An animal study showed that a decrease in fixation stiffness caused a significant increase in the rate of fracture healing in a sheep model [16]. Research shows that micromotion caused by axial compression load is beneficial to fracture healing, and the micromotion distance of $0.2-1.0 \mathrm{~mm}$ is appropriate. If it exceeds $2 \mathrm{~mm}$, it may have a negative effect on fracture healing because excessive interfragmentary motion can lead to hypertrophic callus formation and nonunion $[17,18]$. Under axial compression of $200 \mathrm{~N}$ as the partial weight-bearing condition, both near and far cortex micromotion in the CF-PEEK plate is larger than that of titanium plating construct, but within the optimal range.

The titanium alloy locking plate is the most commonly used plate for lower limb fractures in the clinic.
Meanwhile, the results of this study showed that the strength of the CF-PEEK locking plate is no less than that of the traditional titanium alloy locking plate. This indicated that the new material plate is safe in the treatment of tibial shaft comminuted fracture in theory, although further research is needed.

There are many other advantages of the CF-PEEK material that prompt us to study it further, including: (1) good biocompatibility to reduce allergic reaction to the plate; (2) radiolucency and artifact-free imaging, so we can better observe the reduction quality of the fracture during the operation and the formation of callus after operation; (3) no galvanic corrosion, cold welding, or metal ion release, which can reduce the difficulty of removing the plate; and (4) increased accuracy of radiotherapy dosing in cancer patients, with Christoph et al. reporting that CF/PEEK implants lead to a more reliable and more effective delivery of radiation dose to an osseous target [44]. Thus, the CF-PEEK plate is a more ideal material for bone plates both in biomechanics and in other attributes.

Our study has two potential limitations. First, we investigated axial loading, torsion, and bending individually. Though this enables us to understand the benefits
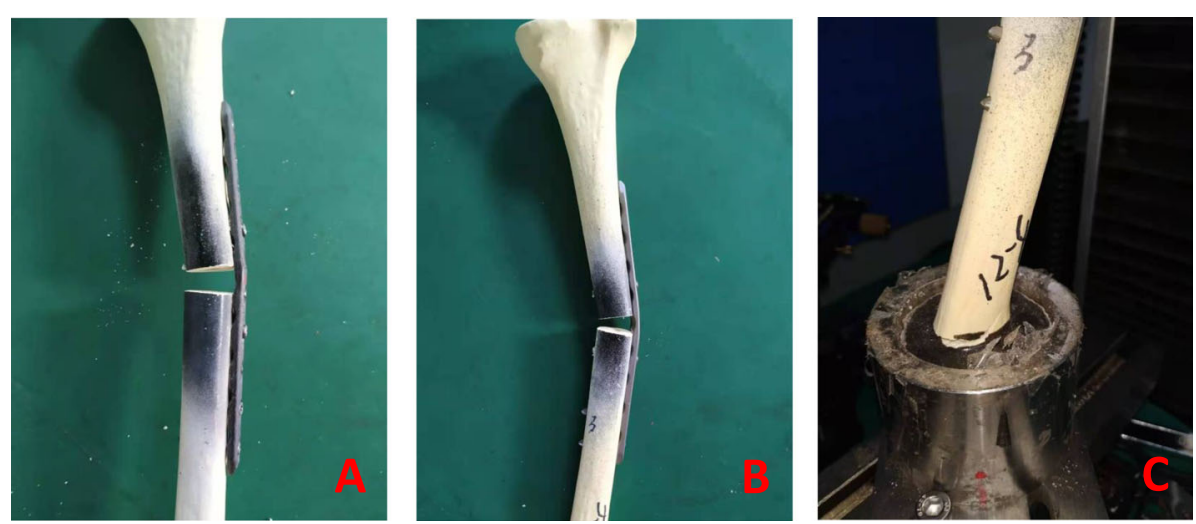

Fig. 6 locking plate constructs failed plate: breakage (a); plate bending (b); fracture at the bone end (c) 

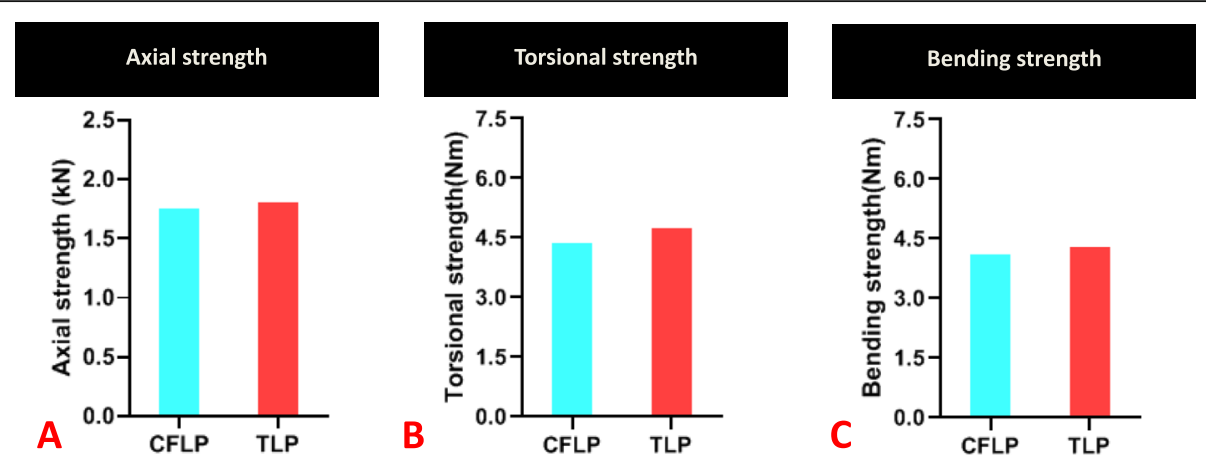

Fig. 7 The strength of the CF-PEEK locking plate was only 2.6\% lower under axial compression than the titanium locking plate $(P<0.05)$, and 7.8\% lower in torsion $(P<0.05)$, and $4.8 \%$ lower in bending $(P<0.05)$

and weaknesses of CF-PEEK locking constructs, loading in clinical situations will be some combination of the above forces with more complex biomechanics. Second, bone quality will also affect the micromotion of the fracture ends after plate fixation. Thus far, we have only carried out biomechanical tests on normal bone; we will conduct relevant tests on osteoporotic bone in the future.

In conclusion, CF-PEEK plates appear to offer an attractive alternative to reduce the stiffness while retaining the strength of bridge plating constructs when interfragmentary motion is desired to promote secondary bone healing. Despite the theoretical benefits of CF-PEEK locking plates, future in vivo studies will be required to evaluate whether CF-PEEK locking plates can better promote formation and maturation of a fracture callus than metal plates.

\section{Abbreviations \\ CF: Carbon fiber; CF-PEEK plate: Carbon fiber reinforced poly-ether-ether-ke- tone composite plate; PEEK: Poly-ether-ether-ketone; \\ AO: Arbeitsgemeinschaftfür Osteosynthesefragen; CFLP: Carbon fiber reinforced poly-ether-ether-ketone composite locking plate; TLP: Titanium alloy locking plate}

\section{Acknowledgements}

We would like to thank the Central Laboratory of First Affiliated Hospital of Soochow University for technical guidance.

\section{Authors' contributions}

Kaihua Zhou conceived the study. Kaihua Zhou and Xiaojian He participated in its design and coordination. Kaihua Zhou, Xingguang Tao, and Fugen Pan analyzed the data and drafted the manuscript. All authors interpreted the data and participated in drafting the text and tables. All authors read and approved the final manuscript.

\section{Funding}

This research receive the funding from Shanghai Municipal Health Bureau (No.: 20174y0159); Bengbu Medical College (No.: BYKY2019263ZD)

\section{Availability of data and materials}

The datasets used and/or analyzed during the current study are available from the corresponding author on reasonable request.

Ethics approval and consent to participate Not applicable
Consent for publication

Not applicable

\section{Competing interests}

The authors declare that they have no competing interests.

\section{Author details}

'Department of Orthopedics, the First Affiliated Hospital of Soochow University, No. 899, Pinghai Road, Soochow 215006, China. ${ }^{2}$ Department of Orthopedics, Qingpu Branch of Zhongshan Hospital affiliated to Fudan University, No. 1158, Gongyuandong Road, Shanghai 201700, China.

Received: 21 August 2020 Accepted: 12 November 2020

Published online: 23 November 2020

\section{References}

1. Chen W, Lv H, Liu S, et al. National incidence of traumatic fractures in China: a retrospective survey of 512187 individuals. Lancet Global Health. 2017;5: e807.

2. Green DP. Rockwood and Green's fractures in adults: Lippincott Williams \& Wilkins; 2010.

3. Perren SM, Allgöwer M, Cordey J, et al. Developments of compression plate techniques for internal fixation of fractures. Prog Surg. 1973;12:152-79.

4. Kolodziej P, Lee FS, Patel A, et al. Biomechanical evaluation of the schuhli nut. Clin Orthop Relat Res. 1998;347:79-85.

5. Ring D, Kloen P, Kadzielski J, et al. Locking compression plates for osteoporotic nonunions of the diaphyseal humerus. Clin Orthop Relat Res. 2004:425:50-4.

6. Lujan TJ, Henderson CE, Madey SM, et al. Locked plating of distal femur fractures leads to inconsistent and asymmetric callus formation[]]. J Orthop Trauma. 2010;24:156-62.

7. Karladani AH, Granhed H, Kärrholm J, et al. The influence of fracture etiology and type on fracture healing: a review of 104 consecutive tibial shaft fractures. Arch Orthop Trauma Surg. 2001;121:325-8. https://doi.org/10. 1007/s004020000252.

8. Fong $\mathrm{K}$, Truong $\mathrm{V}$, Foote $\mathrm{CJ}$, et al. Predictors of nonunion and reoperation in patients with fractures of the tibia: an observational study. BMC Musculoskelet Disord. 2013;14:103. https://doi.org/10.1186/1471-2474-14103.

9. Brinker MR, Hanus BD, Sen M, O'Connor DP. The devastating effects of tibial nonunion on health-related quality of life. J Bone Joint Surg Am. 2013; 95(24):2170-6. https://doi.org/10.2106/JBJS.L.00803.

10. Huang X, Xiao H, Xue F. Clavicle nonunion and plate breakage after locking compression plate fixation of displaced midshaft clavicular fractures. Exp Ther Med. 2020;19(1):308-12. https://doi.org/10.3892/etm.2019.8216.

11. Adam P, Bonnomet F, Ehlinger M. Advantage and limitations of a minimally-invasive approach and early weight bearing in the treatment of tibial shaft fractures with locking plates. Orthop Traumatol Surg Res. 2012; 98(5):564-9.

12. $L v H$, Chang $W$, Yuwen $P$, et al. Are there too many screw holes in plates for fracture fixation? BMC Surg. 2017;17(1):46. 
13. Wang J, Zhang X, Li S, et al. Plating system design determines mechanical environment in long bone mid-shaft fractures: a finite element analysis. J Investig Surg. 2020;33(8):699-708. https://doi.org/10.1080/08941939.2019. 1567875.

14. Kaczmarek J, Bartkowiak T, Schuenemann R, et al. Mechanical performance of a polyaxial locking plate and the influence of screw angulation in a fracture gap model. Vet Comp Orthop Traumatol. 2020;33(1):36-44. https:// doi.org/10.1055/s-0039-1698415.

15. Kubiak EN, Fulkerson E, Strauss E, Egol KA. The evolution of locked plates. J Bone Joint Surg Am. 2006;88(Suppl 4):189-200.

16. Goodship AE, Kenwright J. The influence of induced micromovement upon the healing of experimental tibial fractures. J Bone Joint Surg Br. 1985;67: 650-5.

17. Perren SM. Evolution of the internal fixation of long bone fractures. The scientific basis of biological internal fixation: choosing a new balance between stability and biology. J Bone Joint Surg Br. 2002;84(8):1093-110. https://doi.org/10.1302/0301-620x.84b8.13752.

18. Augat $P$, Penzkofer $R$, Nolte $A$, et al. Interfragmentary movement in diaphyseal tibia fractures fixed with locked intramedullary nails. J Orthop Trauma 2008;22:30-36. Doi: https://doi.org/10.1097/BOT.0b013e31816073cb. PMID:18176162.

19. Doornink J, Fitzpatrick DC, Madey SM, et al. Far cortical locking enables flexible fixation with periarticular locking plates. J Orthop Trauma. 2011; 25(Suppl 1):S29-34.

20. Roderer G, Gebhard F, Duerselen L, et al. Delayed bone healing following high tibial osteotomy related to increased implant stiffness in locked plating. Injury. 2014;45(10):1648-52.

21. Nakahara I, Takao M, Bandoh S, et al. In vivo implant fixation of carbon fiber-reinforced PEEK hip prostheses in an ovine model. J Orthop Res2013; 31:485-492. Doi: https://doi.org/10.1002/jor.22251. PMID:23097319.

22. Tedesco G, Gasbarrini A, Bandiera S,et al. Composite PEEK/carbon fiber implants can increase the effectiveness of radiotherapy in the management of spine tumors. J Spine Surg. 2017;3:323-329.Doi: https://doi.org/10.21037/ jss.2017.06.20. PMID:29057339.

23. Ringel F, Ryang YM, Kirschke JS,et al. Radiolucent carbon fiber-reinforced pedicle screws for treatment of spinal tumors: advantages for radiation planning and follow-up imaging. World Neurosurg 2017;105:294-301. Doi: https://doi.org/10.1016/j.wneu.2017.04.091. PMID:28478252.

24. Wang $\mathrm{N}$, Xie $\mathrm{H}, \mathrm{Xi}$, et al. A study to compare the efficacy of polyether ether ketone rod device with titanium devices in posterior spinal fusion in a canine model. J Orthop Surg Res 2017;12:40. Doi: https://doi.org/10.1186/ s13018-017-0543-x. PMID:28279204

25. Boriani S, Tedesco G, Ming L, et al. Carbon-fiber-reinforced PEEK fixation system in the treatment of spine tumors: a preliminary report. Eur Spine $J$ 2017:27:1-8.Doi: https://doi.org/10.1007/s00586-017-5258-5. PMID:28815357.

26. Katthagen JC, Ellwein A, Lutz $\mathrm{O}$, et al. Outcomes of proximal humeral fracture fixation with locked CFR-PEEK plating. Eur J Orthop Surg Traumatol. 2017;27(3):351-8. https://doi.org/10.1007/s00590-016-1891-7.

27. Katthagen JC, Schwarze M, Warnhoff $M$, et al. Influence of plate material and screw design on stiffness and ultimate load of locked plating in osteoporotic proximal humeral fractures. Injury. 2016;47(3):617-24. https:// doi.org/10.1016/j.injury.2016.01.004.

28. Gallagher EA, Lamorinière S, McGarry P. Finite element investigation into the use of carbon fibre reinforced PEEK laminated composites for distal radius fracture fixation implants. Med Eng Phys. 2019;67:22-32. https://doi. org/10.1016/j.medengphy.2019.03.006

29. Allemann F, Halvachizadeh S, Rauer T, et al. Clinical outcomes after carbonplate osteosynthesis in patients with distal radius fractures. Patient Saf Surg. 2019;13:30. Published 2019 Sep 4. doi:https://doi.org/10.1186/s13037-0190210-8.

30. Mehboob H, Son D S, Chang S H. Finite element analysis of tissue differentiation process of a tibia with various fracture configurations when a composite intramedullary rod was applied. Composites Sci Technol. 2013; 80(5):55-65. Doi: https://doi.org/10.1016/j.compscitech.2013.02.020.

31. Bottlang M, Doornink J, Fitzpatrick DC, et al. Far cortical locking can reduce stiffness of locked plating constructs while retaining construct strength. J Bone Joint Surg Am 2009;91:1985-1994.Doi: https://doi.org/10.2106/JBJS.H. 01038.PMID:32189888.

32. Gösling T, Schandelmaier P, Marti A, et al. Less invasive stabilization of complex tibial plateau fractures: a biomechanical evaluation of a unilateral locked screw plate and double plating. J Orthop Trauma. 2004;18(8):546-51. https://doi.org/10.1097/00005131-200409000-00011.

33. Hasenboehler E, Smith WR, Laudicina L,et al. Fatigue behavior of Ilizarov frame versus tibial interlocking nail in a comminuted tibial fracture model: a biomechanical study. J Orthop Surg Res. 2006;1:16. Published 2006 Dec 11. doi:https://doi.org/10.1186/1749-799X-1-16.

34. Egol KA, Kubiak EN, Fulkerson E, et al. Biomechanics of locked plates and screws. J Orthop Trauma. 2004;18:488-93.

35. Gardner MJ, Nork SE, Huber P, et al. Stiffness modulation of locking plate constructs using near cortical slotted holes: a preliminary study. J Orthop Trauma 2009;23(4):281-287.Doi: https://doi.org/10.1097/BOT. Ob013e31819df775. PMID:19318872.

36. Uhthoff HK, Poitras P, Backman DS. Internal plate fixation of fractures: short history and recent developments. J Orthop Sci. 2006;11:118-26.

37. Herrera DA, Kregor PJ, Cole PA, et al. Treatment of acute distal femur fractures above a total knee arthroplasty: systematic review of 415 cases (1981-2006). Acta Orthop. 2008;79:22-7.

38. Ahmad M, Nanda R, Bajwa AS, et al. Biomechanical testing of the locking compression plate: when does the distance between bone and implant significantly reduce construct stability? Injury. 2007;38:358-64.

39. Kowalski MJ, Schemitsch EH, Harrington RM, et al. A comparative biomechanical evaluation of a noncontacting plate and currently used devices for tibial fixation. J Trauma. 1996;40:5-9.

40. Stoffel K, Dieter U, Stachowiak G, et al. Biomechanical testing of the LCP_how can stability in locked internal fixators be controlled? Injury. 2003:34(Suppl 2):B11-9.

41. Razavi M, Fathi M, Savabi O, et al. Biodegradable Magnesium Bone Implants Coated with a Novel Bioceramic Nanocomposite. Materials (Basel). 2020; 13(6):1315. Published 2020 Mar 13. doi:https://doi.org/10.3390/ma13061315.

42. Krüger R, Groll J. Fiber reinforced calcium phosphate cements - on the way to degradable load bearing bone substitutes? Biomaterials.2012;33(5):58875900. Doi: 13.1016/j.biomaterials.2012.04.053.PMID:22632767.

43. Dorozhkin, Sergey. Calcium orthophosphates as bioceramics: state of the art. J Funct Biomater 2010;1: 22-107. Doi:https://doi.org/10.3390/jfb1010022. PMID:24955932.

44. Laux CJ, Villefort C, Ehrbar S, et al. Carbon Fiber/Polyether Ether Ketone (CF) PEEK) Implants Allow for More Effective Radiation in Long Bones. Materials (Basel). 2020;13(7):1754. Published 2020 Apr 9. doi:https://doi.org/10.3390/ ma13071754.

\section{Publisher's Note}

Springer Nature remains neutral with regard to jurisdictional claims in published maps and institutional affiliations.

Ready to submit your research? Choose BMC and benefit from:

- fast, convenient online submission

- thorough peer review by experienced researchers in your field

- rapid publication on acceptance

- support for research data, including large and complex data types

- gold Open Access which fosters wider collaboration and increased citations

- maximum visibility for your research: over $100 \mathrm{M}$ website views per year

At BMC, research is always in progress.

Learn more biomedcentral.com/submission 